\title{
MECHANICAL PROPERTIES OF GLASS REINFORCED HYDROXYAPATITE
}

Y.R. Muslim, J. Knowles, J. Howlett. Mechanical properties of Glass Reinforced Hydroxyapatite. Annal Dent Univ Malaya 2005; 12: 31-36.

\begin{abstract}
Hydroxyapatite (HA) has been increasingly used in biomedical applications due to its biocompatibility with living tissues. However, its use is limited to low load bearing areas due to the poor mechanical properties compared to bone. The aim of this project is to improve the mechanical properties of synthetic HA by optimising the processing method and also by using a phosphate based glass as a sintering aid to develop Glass Reinforced Hydroxyapatite (GR-HA). A phosphate based glass containing $\mathrm{CaO}, \mathrm{P}_{2} \mathrm{O}_{5}$ and $\mathrm{CaF}_{2}$ was incorporated into $\mathrm{HA}$ at $2.5 \mathrm{wt} \%$ and $5 \mathrm{wt} \%$ additions during the milling process prior to sintering at $1300^{\circ} \mathrm{C}$. The flexural strength mean values for GR-HA ranged from $80 \mathrm{MPa}$ to $110 \mathrm{MPa}$. Pure HA exhibited a much lower flexural strength mean value ranging from $66 \mathrm{MPa}$ to $79 \mathrm{MPa}$. The improved mechanical properties were associated with the occurrence of residual stress as a result of decomposition of HA to b-Tricalcium Phosphate (TCP) and in $5 \mathrm{wt} \% \mathrm{GR}$ HA to a-Tricalcium Phosphate (TCP).
\end{abstract}

Key words: hydroxyapatite, glass reinforced hydroxylate $\left(2.5 \mathrm{wt} \%\right.$ \& $\left.5 \mathrm{wt}^{\mathrm{0}} \%\right)$.

\section{INTRODUCTION}

There has been a great interest in the use of ceramics particularly HA, in biomedical applications due to its very good biological performance. The clinical applications of bioceramics include the repair of skeletal system, composed of bones, joints and teeth and to augment both hard and soft tissues (Hench et al., 1993).

Hydroxyapatite (HA: $\left.\mathrm{Ca}_{10}\left(\mathrm{PO}_{4}\right)_{6}(\mathrm{OH})_{2}\right)$ closely resembles the mineralised phase of bone and tooth, the structure to which closely similar to the crystallographic form of apatite (deGroot et al., 1985). Synthetic HA has found success in hard tissue surgery (Wolford et al., 1987) as it is capable of undergoing bonding osteogenesis when implanted in vivo. It is also able to bond with the host tissue by stimulating a specific biological response at the host/biomaterial interface. Nevertheless, its use has been limited to low load bearing areas due to its poor mechanical properties particularly toughness and bending strength.
Original Article

Y.R. Muslim¹, J. Knowles², J. Howlett. ${ }^{3}$

${ }^{1}$ Master of Clinical Dentistry (Prosthodontics),

Eastman Dental Institute,

University College London, London.

2 Department of Biomaterials,

Eastman Dental Institute,

University College London, London.

${ }^{3}$ Department of Prosthetics,

Eastman Dental Institute,

University College London, London.

Corresponding author - Y.R. Muslim

Faculty of Dentistry,

University of Malaya

Several attempts have been made to combine the advantageous properties of HA with bioactive glass (Knowles et al., 1996, Knowles et al., 1996) and to optimise the processing and sintering regimens (Puanjindanetr et al., 1994). A glass reinforced hydroxyapatite (GR-HA) composite can be produced by the addition of a glass such as phosphate based glass which serves as a mean of improving strength and biocompatibility (Knowles et al., 1996, Tancred et al., 1998, Lopes et al., 1999, Georgiou et al., 2001). It has been reported that the inclusion of phosphate based glasses produce significant improvement in mechanical properties (Santos et al, 1995, Lopes et al., 1998, Tancred et al., 1998) such as flexural strength and fracture toughness of between three and fourfold (Knowles et al., 1993).

Phosphate based glasses which have a similar composition to HA, have been incorporated into HA to form GR-HA. The role of glass which acts as a sintering aid enhances densification thus reduces porosity. Besides, the inclusion of glass to HA promotes decomposition to secondary phases in which it results in microstructural changes. The presence of secondary phases can have a beneficial or detrimental effect on the mechanical properties of HA composite.

The degree of decomposition and subsequent phase changes and the resultant improved mechanical properties are influenced by factors such as sintering temperature, glass composition, $\mathrm{wt} \%$ glass addition and apatite powder (Knowles et al., 1993, Knowles et al., 1996).

The purpose of the study is to identify a glass reinforced hydroxyapatite (GR-HA) composite with 
optimal mechanical strength, specifically flexural strength.

\section{MATERIALS AND METHODS}

Preparation of phosphate glass ( $\mathrm{CaO}-\mathrm{P}_{2} \mathrm{O}_{5}-\mathrm{CaF}_{2}$ )

The phosphate based glass was produced by standard forming techniques. The ternary glass was produced using starting reagents consisted of the following compounds; $\mathrm{P}_{2} \mathrm{O}_{5}, \mathrm{CaHPO}_{4}$, and $\mathrm{CaF}_{2}$. The weight of each constituent was $15.09 \mathrm{~g}, 14.44 \mathrm{~g}$ and $2.93 \mathrm{~g}$ respectively. They were mixed thoroughly and placed in a platinum crucible and melted at the different temperatures and periods of time shown below:
1. $600^{\circ} \mathrm{C}$ for $1 / 2$ hour
2. $700^{\circ} \mathrm{C}$ for $1 / 2$ hour
3. $800^{\circ} \mathrm{C}$ for $1 / 2$ hour
4. $1150^{\circ} \mathrm{C}$ for 1 hour

The molten glass was poured onto a steel plate and allowed to cool. The resulting glass was then ground to a fine powder using a ball and agate grinder.

Preparation of hydroxyapatite and glass reinforced hydroxyapatite

Basically, there were three different sample groups that were used in the study;

- Group A-pure HA

- Group B- 2.5wt\% GR-HA

- Group C- 5wt\% GR-HA

\section{Milling procedures}

Group A (pure HA) was prepared using $200 \mathrm{~g}$ of $\mathrm{HA}$ and $300 \mathrm{ml}$ of methanol which were placed into a porcelain mill pot and the mixture was then wet milled for 24 hours. Methanol was used as a solvent and aided in grinding. The HA slip that was formed during milling was left to dry in a drying cabinet at approximately $70^{\circ} \mathrm{C}$ for 24 hours to burn off the methanol.

Group B and $\mathbf{C}$ which were GR-HA composites were prepared in a similar way as the above. However, they differed in the amount of the glass added and weight percentage of glass to HA. Group B (2.5wt $\%$ glass) consisted of $5 \mathrm{~g}$ of glass and $195 \mathrm{~g}$ of HA whereas group $\mathrm{C}(5 \mathrm{wt} \%$ glass $)$ consisted of $10 \mathrm{~g}$ of glass and $190 \mathrm{~g}$ of HA.

\section{Preparation of specimen disc}

The resulting coarse powder from the three samples were sieved to less than $75 \mathrm{~mm}$ using a vibratory sieved shaker through Endecotts sieves of size $1000 \mu \mathrm{m}, 200 \mu \mathrm{m}, 150 \mu \mathrm{m}, 100 \mu \mathrm{m}$ and $75 \mu \mathrm{m}$. The powder from each of the groups was then weighed on the Mettler Toledo balance. Four grams from each group was weighed in a weighing pot before pressing of the specimens were carried out.
Each specimen disc was fabricated by pressing $4 \mathrm{~g}$ of powder using a steel die, set to produce $30 \mathrm{~mm}$ diameter discs. The powder was uniaxially pressed, using a hydraulic press at 20 tons and the disc produced was removed from the die. The discs were stored in a plastic container with cotton wool around them. Between samples the steel die was cleaned and any excess powder removed using Azowipe (alcoholbased solvent) and Scalpel blade.

The discs were placed in an oven at a temperature approximately $70^{\circ} \mathrm{C}$ and dried for a minimum of 24 hours prior to firing. Alumina tiles were used to place the discs for sintering. The discs were fired at $4^{\circ} \mathrm{C}$ per minute ramp rate up to $1300^{\circ} \mathrm{C}$. When the set temperature $\left(1300^{\circ} \mathrm{C}\right)$ was reached, it was maintained for 1 hour, followed by furnace cooling.

The sintered discs were assessed and any cracked discs were discarded. The number of specimen discs obtained for each group A, B, C was 39, 37 and 43 respectively. The discs were measured for the average thickness (three times at different places) and diameter using digital callipers. The mean thickness of each disc was measured. The specimens from each one group at a time were pressed, sintered and tested before moving to the other groups.

\section{Mechanical testing}

The sintered discs were tested in biaxial flexure, using a concentric ring jig with a load ring diameter of $10 \mathrm{~mm}$ and an outer supporting ring diameter of $20 \mathrm{~mm}$. Specimen discs were tested for flexural strength for each GR-HAs $(2.5 \mathrm{wt} \%$ and $5 \mathrm{wt} \%)$ and pure HA on Dartec mechanical testing machine at a crosshead speed of $5 \mathrm{~mm} / \mathrm{min}$ to failure. Each disc was placed in the center of the concentric jig ensuring that the load exerted was right in the middle of the disc. The machine was calibrated each time before a specimen was tested. The point of failure was indicated by a maximum load $(F)$ value taken from the load displacement graph. The flexural bend strength in biaxial bending was determined by the following equation:

$$
\sigma_{\mathrm{r}}=\frac{3 \mathrm{~F}(1+\mathrm{v})}{4 \pi \mathrm{t}^{2}}\left[1+\ln \frac{\mathrm{r}_{2}}{\mathrm{r}_{1}}+\frac{1-\mathrm{v}}{1+\mathrm{v}}\left\{1-\frac{\mathrm{r}_{1}^{2}}{2 \mathrm{r}_{2}{ }^{2}}\right\} \frac{\mathrm{r}_{2}^{2}}{\mathrm{r}^{2}}\right]
$$

Where

$$
\begin{array}{ll}
\mathrm{F} & : \text { load } \\
\mathrm{t} & : \text { sample thickness } \\
\mathrm{v} & : \text { Poisson's ratio } \\
\mathrm{r}_{1} & : \text { radius of loading ring } \\
\mathrm{r}_{2} & : \text { radius of supporting ring } \\
\mathrm{r} & : \text { radius of disc specimen }
\end{array}
$$

\section{X-ray Diffractometer}

Tested samples (HA, 2.5wt $\%$ GR-HA and $5 w t \%$ GR-HA) were ground to a fine powder, each was placed in a specimen holder and analysed on a diffractometer with $\mathrm{Ni}$ filtered $\mathrm{CuKa}$ radiation at 


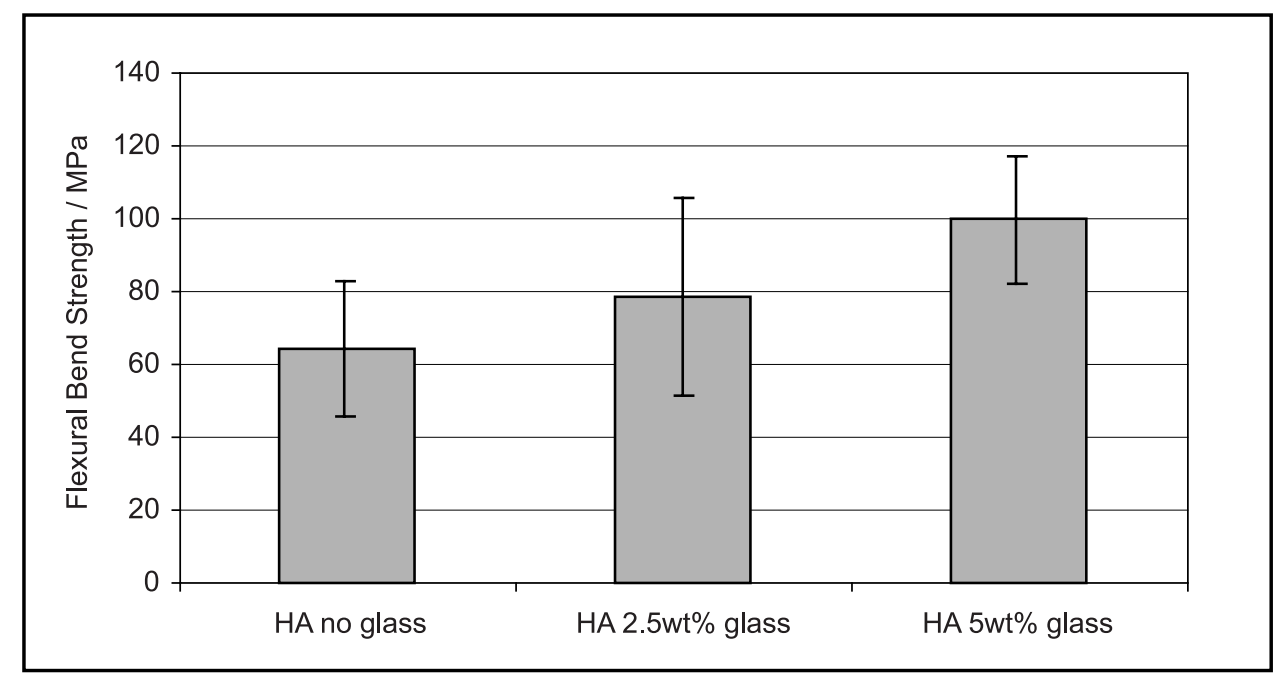

Figure 1: Flexural strength: mean values of $\mathrm{HA}$ and GR-HA with $2.5 \mathrm{wt} \%$ and $5 \mathrm{wt} \%$ glass addition $(\mathrm{I}=$ standard deviation $)$.

$40 \mathrm{kV}$ and $30 \mathrm{~mA}$. The powder from each samples was scanned between $10<2 \theta<100^{\circ}$ with a step size of $0.02^{\circ}$ and count time of $12 \mathrm{~s}$ using a flat plate geometry. The collected diffraction patterns were refined in order to quantify the phases present (i.e. HA, $\alpha$-TCP and $\beta$-TCP).

\section{Structure Refinement}

The structure refinement was carried out using General Structure Analysis Software (GSAS). The collected diffraction patterns of the sample groups were refined against the standard model patterns for each phase. The standard model for each of the three phases was determined from the Daresbury Crystal Structure Database. The HA model was based on the single crystal structure determination with $\mathrm{P}_{3} / \mathrm{m}$ space group and lattice parameters of $\mathrm{a}=9.45 \AA$ and $\mathrm{c}=6.88 \AA$. The second phase $\beta$-TCP consists of a $\mathrm{R}_{3} \mathrm{CH}$ space group and lattice parameters of approximately $\mathrm{a}=10.4 \AA$ and $\mathrm{c}=$ $37.4 \AA$. The standard model used to refine $\alpha$-TCP was based on the $\mathrm{P}_{2} 1 / \mathrm{a}$ space group and unit cell dimensions of $\mathrm{a}=12.887 \AA, \mathrm{b}=27.28 \AA \mathrm{c}=15.219 \AA$, and $\beta=126.2^{\circ}$.

The GSAS software calculated the phase weight percentage and the theoretical density (assuming there was no porosity). The theoretical densities determined represented a whole set specimen from each group and so therefore there was no standard deviation associated with them. From the data for the measured density and the theoretical density, the porosity is therefore calculated using;

$$
\frac{\text { recorded density }}{\text { theoretical density }} \times 100(\%)=\text { porosity }
$$

\section{Data collection}

Data collected were tabulated and analysed (flexural strength, mean values and standard deviations) using Microsoft Excel. Using the same software, tables and graphs were made.

\section{RESULTS}

\section{Flexural strength}

The flexural strength mean values determined for HA P120 and GR-HA composites with different glass weight additions are shown in Figure 1. The mean value of flexural strength for HA was $64.29 \mathrm{MPa}$ which was the lowest calculated value compared to $2.5 \mathrm{wt} \%$ and $5 \mathrm{wt} \%$ GR-HA; $78.84 \mathrm{MPa}$ and $99.74 \mathrm{MPa}$ respectively. However, the $2.5 \mathrm{wt} \%$ GR-HA showed the largest variation in the collected data as the standard deviation was calculated at 27.2MPa. The standard deviation for $\mathrm{HA}$ and $5 \mathrm{wt} \%$ GR-HA were $18.44 \mathrm{MPa}$ and $17.6 \mathrm{MPa}$ respectively.

\section{Structure Refinement}

From the Rietveld refinement the phase element fraction can be refined as a variable and measured. The Rietveld refinement assumes that there is no porosity in the sample, therefore, the overall theoretical densities that are determined may not necessarily correspond to the actual densities measured. The results from the structure refinement using General Structure Analysis Software are summarised as shown in Table 2 and Figure 2.

\section{Phase fraction}

Table 2. Shows the phase fractions of HA and GR-HAs

\begin{tabular}{lccc}
\hline Sample Groups & HA phase & b-TCP & a-TCP \\
\hline HA & 1 & 0 & 0 \\
2.5wt\% GR-HA & 0.852 & 0.148 & 0 \\
5wt\% GR-HA & 0.444 & 0.312 & 0.244 \\
\hline
\end{tabular}




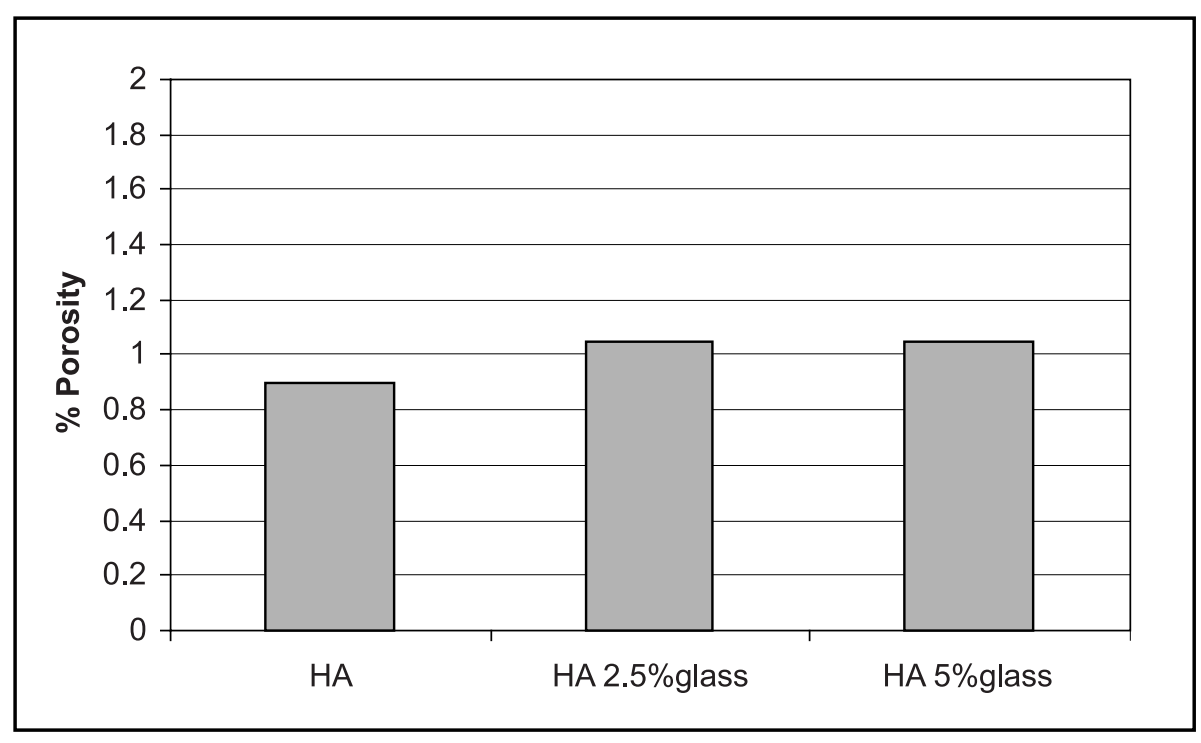

Figure 2: Porosity values for HA and GR-HA with $2.5 \mathrm{wt} \%$ and $5 \mathrm{wt} \%$ glass additions.

Table 2 shows the phase fractions of specifically HA, b-TCP and a-TCP taken from specimens sintered at $1300^{\circ} \mathrm{C}$. From the results obtained, it can be said that decomposition to secondary phases occurred in GR-HAs. It was demonstrated that the higher the glass additions, the more the secondary phases $(\beta$, $\alpha$-TCP) were formed. There was a considerable amount of secondary phases present specifically in $5 \mathrm{wt} \%$ GR-HA. Also, $\alpha$-TCP was only formed in $5 \mathrm{wt} \%$ glass addition which indicated the relationship of the amount of glass added with the degree of decomposition.

\section{$\%$ Porosity}

The $2.5 \mathrm{wt} \%$ and $5 \mathrm{wt} \%$ GR-HA both appeared to show higher porosity values compared to HA.

\section{DISCUSSION}

\section{Flexural strength of GR-HAs}

The findings from the present study clearly demonstrated the correlation between phosphate glass $\mathrm{wt} \%$ additions and improved mechanical properties particularly, flexural strength (Figure1). The flexural strength mean values for HA and GRHA containing $2.5 \mathrm{wt} \%$ and $5 \mathrm{wt} \%$ of phosphate based glass differed considerably. Both $2.5 \mathrm{wt} \%$ and $5 \mathrm{wt} \%$ GR-HA showed a marked increased in the mean flexural strength values as compared to HA. In general, these were in agreement with the previous studies that investigated the reinforcing effects of GR-HAs at different sintering temperatures, wt $\%$ glass additions and glass composition (Knowles et al., 1993, Knowles et al., 1996).

The addition of glass to HA acts as a sintering aid, which enhances densification and consequently, reduces porosity. The liquid phase sintering mechanism which occurs as a result of glass addition accelerates inter-particulate diffusion and bonding, therefore causing elimination of porosity and shrinkage (Richerson, 1992, Knowles et al., 1996, Jha et al., 1996, Georgiou et al., 2001). However, the effects are not apparent in the present study as they are further complicated by the occurrence of decomposition and phase changes that can also have a detrimental and beneficial effect on the mechanical properties (Knowles et al., 1996).

It was noticed that both GR-HA containing $2.5 \mathrm{wt} \%$ and $5 \mathrm{wt} \%$ phosphate glass exhibited an increase in porosity percentage values (Figure 2). Pores may occur in the HA structure during grain growth process which is governed by the glass reactivity and sintering rate. The higher the glass reactivity and sintering rate, the faster the grain boundary migration. In this particular instance, it could be that the grain boundary migration may occur faster than pore elimination. Besides, higher porosity values in GR-HA could be related to low glass reactivity and hampered the sintering process which resulted in slower atomic diffusion (Lopes et al., 1996).

The increased flexural strength demonstrated could be associated with the role of glass in promoting decomposition of HA which occurs at the temperature between $1200-1350^{\circ} \mathrm{C}$. When the glass composition particularly $\mathrm{Ca} / \mathrm{P}$ ratio moves towards the $\mathrm{HA} \mathrm{Ca} / \mathrm{P}$ ratio of 1.67 , the phase inversions that occur are reduced as indicated by the lower $\beta$-TCP and absence of $\alpha$-TCP. However, the effects of different glass composition and sintering temperature are not applicable to the present study as similar glass and sintering temperature were used for all the sample groups.

Another effect of the addition of glass to HA, is that its acts as a grain growth inhibitor, preventing 
cracks which might propagate within the material (Santos et al., 1995). This mechanism may be associated with the presence of secondary phases which causes the development of compressive stress within the lattice. The resultant stress thus, has a strengthening effect on the material. One may come to the assumption that the role of secondary phases in this instance, is similar to that of partially stabilised zirconia with the partial stabilisation acting as a crack stopping mechanism in the ceramics.

For this glass system, it can be suggested that both porosity and phase transformation are the influential factors in the outcome of the mechanical properties. However, the present results appear to suggest that the overall improvement in flexural strength for glass reinforced HA, is predominantly associated with phase decomposition and subsequent phase inversion.

\section{CLINICAL SIGNIFICANCE}

The clinical reliability of ceramics, HA in particular, has not been fully realised. This is due to the brittle nature of HA and the distribution of flaws within the structure which plays an important role in determining the mechanical properties of ceramics. The present study has allowed a better understanding of the reinforcing effect of phosphate based glass on HA. The report on the properties of GR-HA can also be made based on this finding whether the material is suitable to be used as prosthesis in Orthopedics and Dentistry because the clinical reliability of the ceramic prosthesis can be compromised if fracture occurs at low stress values. Their clinical applications are related to the repair of the skeletal system, composed of bones, joints and teeth and to augment both hard and soft tissues (Wolford et al., 1987, Hench et al., 1993). They also found that the hydroxyapatite reinforced materials provided good volume augmentation with absence of any adverse effects associated with the use of these materials.

Based on the findings, it is clearly demonstrated that the role of glass outlined in the study suggested a promising development of ceramics that have a superior biocompatibility as well as bioactivity which can be implemented as implant prostheses. In dentistry, the use of bioactive HA for-implant coating has attracted considerable interest, particularly in the use of plasma spraying to combine the superior mechanical performance of the metal component with the excellent biological response of hydroxyapatite (Ji et al., 1993).

Plasma sprayed HA has been thought to significantly improve bone ingrowth by crystallographic changes in calcium phosphates (Ellies et al., 1992), while at the same time act as a biological barrier against toxic release from the metallic substrate into the body (Ji et al., 1993). Therefore, the findings from the present study could be used in the development of an implant with high mechanical strength with good biocompatibility and bioactivity.

\section{FUTURE STUDY}

The $\mathrm{wt}^{\mathrm{O}} \%$ glass addition is the only variable introduced in the present study. This has limited the findings to one particular sintering temperature and glass composition. For future study, the mechanical properties of GR-HA could be investigated at different sintering temperatures using different glass compositions and $\mathrm{wt} \%$ glass additions. Also, different types of HA powder could be used to find the effect of apatite powder preparation on the mechanical properties of HA composite.

The effect of grain size and pore distribution have not been investigated in detail in this study. Therefore, SEM (scanning electron micrograph) analysis and grain size distribution may be helpful in understanding the effect grain growth inhibition caused by the presence of glass in the HA. In the same way, fractographic analysis can be carried out on each tested specimens which are labeled prior to testing. This will allow the tested specimens to be analysed individually. This is of vital importance as it may assist in investigating the mixed mode of failure in ceramics.

The mechanical properties of ceramics are greatly influenced by the occurrence of pores within its structure. The development of pores may be minimised by preparing the specimens under vacuum (hot pressing). A future study could compare the effect of different specimen preparations on the mechanical properties of the ceramics.

\section{CONCLUSIONS}

- The amount of secondary phases presence was directly proportional to the increased in flexural strength mean values and the degree of HA decomposition and subsequent phase inversion.

- $5 \mathrm{wt} \%$ GR-HA appeared to show the greatest reinforcing effects.

\section{REFERENCES}

de Groot, K., and Le Geros, R. (1988). Position papers in Bioceramics: Materials Characteristics versus In-Vivo Behaviour, P. Ducheyne and $J$. Lemons eds. Ann. New York Acad. Sci., Vol. 523, pp.227, 268, 272. 
Georgiou, G., Knowles, J.C. (2001) Glass reinforced hydroxyapatite for hard tissue surgery-Part 1: mechanical properties. Biomaterials 22, 2811-15.

Georgiou, G. (2002). Development of Glass Reinforced Hydroxyapatite for Hard Tissue Surgery. Phd thesis, University College London.

Hench, L.L., Wilson, J. (1993). An introduction to bioceramics. Advanced series in ceramics. Vol. 1: Singapore:World Scientific.

Jha, L.J., Santos, J.D., \& Knowles, J.C. (1996). Characterisation of apatite layer formation on $\mathrm{P}_{2} \mathrm{O}_{5^{-}}$ $\mathrm{CaO}-\mathrm{Na}_{2} \mathrm{O}$, and $\mathrm{P}_{2} \mathrm{O}_{5}-\mathrm{CaO}-\mathrm{Al}_{2} \mathrm{O}_{3}$ glass hydroxyapatite composites. Journal of Biomedical Materials Research 31, 481-86.

Knowles, J.C, Abrahams, I., Bonfield, W. (1993). Effect of reinforcing glass composition on phase transformation and crystallographic parameters in hydroxyapatite. Bioceramics 6,191-96.

Knowles, J.C., Gross, K..A., Berndt, C.C. and .Bonfield, W. (1996). Structural Changes of Thermally Sprayed Hydroxyapatite Investigated by Rietveld Analysis. Biomaterials 17(6): 639-45.

Knolwes, J.C., Talal, S. \& Santos, J.D. (1996). Sintering effects in a glass reinforced hydroxyapatite. Biomaterials 17, 1437-42.

Knowles, J.C, Abrahams, I., Bonfield, W. (1993). Effect of reinforcing glass composition on phase transformation and crystallographic parameters in hydroxyapatite. Bioceramics 6, 191-96.

Lopes, M.A., Santos, J.D., Monteiro, F.J., Knowles, J.C. (1998). Glass-reinforced hydroxyapatite: a comprehensive study of the effect of glass composition on the crystallography of the composites. Biomedical Materials Research 39(2), 244-51.

Lopes, M., Monteiro, F.J., Santos, J.D. (2000). Glassreinforced hydroxyapatite composites: fracture toughness and hardness dependence on microstructural characteristics. Biomaterials 20, 2085-90.

Puanjindanetr, S., Best, S.M., Bonfield, W. (1994). Characterisation and sintering of precipitated hydroxyapatite. British Ceramic Transactions 93(3), 96-9.

Richerson, D.W. (1992). Modern Ceramic Engineering, Second edition, Marcel Dekker, Inc.

Santos, J.D., Reis, R.L., Monteiro, F.J., Knowles, J.C., Hastings, G.W. (1995). Liquid phase sintering of hydroxyapatite by phosphate and silicate glass additions: structure and properties of composites. Journal of Materials in Medicine 6, 348-52.

Santos, J.D., Silva, P.L., Knowles, J.C., Talal, S., Monteiro, F.J. (1996) Reinforcement of hydroxyapatite by adding $\mathrm{P}_{2} \mathrm{O}_{5}-\mathrm{CaO}$ glasses with $\mathrm{Na}_{2} \mathrm{O}, \mathrm{K}_{2} \mathrm{O}$ and $\mathrm{MgO}$. Journal of Materials ScienceMaterials in Medicine 7(3), 187-9.

Tancred, D.C., Mccormack, B.A.O., Carr, A.J. (1998). A quantitave study of the sintering and mechanical properties of hydroxyapatite/phosphate glass composites. Biomaterials 19, 1735-43.

Wolford, L.M., Wardrop, R.W., Hartog, J.M. (1987). Coralline porous hydroxyapatite as a bone graft substitute in orthognathic surgery. Journal of Oral Maxillofacial Surgery 45, 1034-42. 